\title{
Hydatid cysts of the lung
}

\author{
J D Widdrington, ${ }^{1}$ C Echevarria, ${ }^{2} \mathrm{M}$ Bone, ${ }^{2} \mathrm{R}$ Ellis ${ }^{3}$
}

${ }_{1}^{1}$ Department of Medicine, Royal Victoria Infirmary, Newcastle-Upon-Tyne, UK

${ }^{2}$ Department of Respiratory Medicine, South Tyneside District Hospital, South Shields, UK

${ }^{3}$ Department of Radiology, South Tyneside District Hospital, South Shields, UK

Correspondence to J D Widdrington, john_widd@hotmail.com

\begin{abstract}
Summary
Cystic hydatid disease is a zoonosis caused by infection with the larval cysts of Echinococcus granulosus. Cysts commonly develop in the liver and lungs. Diagnosis in non-endemic regions is often delayed due to a failure to consider hydatidosis. This results from a non-specific presentation and a failure to record an accurate geographical history. The diagnosis requires integrating an appropriate index of suspicion with correct interpretation of imaging and serological tests.

In our case, a 44-year-old woman of Yemeni origin presented to a UK hospital with chest pain, pruritus and weight loss. Following detection of pulmonary nodules, a CT-guided biopsy was carried out to exclude malignancy. latrogenic cyst rupture precipitated an acute eosinophilic pleurisy. Cystic hydatid disease was subsequently diagnosed following strongly positive hydatid serological tests.

This case illustrates the importance of considering diagnoses appropriate to an individual's geographical history particularly in the context of rising immigration and foreign travel.
\end{abstract}

\section{BACKGROUND}

In the UK hydatid cysts are often initially mistaken for other pathologies due to a failure to consider the diagnosis. ${ }^{1}$ This case of delayed diagnosis of pulmonary hydatid cysts involves a Yemeni woman living in the North East of England and highlights ongoing changes in the demographics of the British population. In recent times there has been a steady rise in immigration, particularly to major cities outside London, and foreign travel by UK residents to tropical areas is also increasing. ${ }^{2}$ In these circumstances, an accurate and detailed geographical history is essential to ensure that we consider all diagnoses that are compatible with the circumstances of the individual patient.

\section{CASE PRESENTATION}

A 44-year-old woman presented with a 3-month history of non-specific right-sided chest pain associated with generalised pruritus and weight loss. Over the past few weeks she had developed a breast mass. She was a smoker with a 20 -pack a year history but had no significant past medical history. Originally from Yemen, she had lived in North East England for several years but frequently returned to the Middle East; the last visit was 6 months prior to this presentation. Initial examination revealed several soft breast lumps but no other abnormalities.

\section{INVESTIGATIONS}

Initial blood tests and mammogram were normal. However, a chest radiograph was reported as showing a $3.5 \mathrm{~cm}$ nodule in the right lung lower zone and a $1.5 \mathrm{~cm}$ nodule in the left lung lower zone. A CT scan of her thorax confirmed these findings and concluded that the appearances were consistent with inflammatory changes or malignancy.

Following a CT-guided biopsy of the right lower lobe nodule our patient deteriorated suddenly, developing pro- gressive dyspnoea associated with pleurisy, fever, wheeze and haemoptysis. At this stage, blood tests revealed an eosinophilia $\left(3.4 \times 10^{9} /\right.$ litre $)$ and an elevated $\mathrm{C}$ reactive protein (32.9 mg/litre). A right-sided pleural effusion was detected on a chest radiograph and analysis of the pleural fluid revealed an exudative effusion with an inflammatory infiltrate but no organisms identified. There was no evidence of malignancy in the pleural fluid or lung biopsy specimens.

A liver ultrasound scan detected a $35 \mathrm{~mm}$ lesion in the right lobe of the liver and at this point we proceeded to analyse hydatid serology. Both hydatid ELISA (1:646) and hydatid indirect haemagglutination $(>640)$ assays were strongly positive.

\section{TREATMENT}

Following the results of the hydatid serology assay, treatment with praziquantel ( $40 \mathrm{mg} / \mathrm{kg}$ for 2 weeks) in combination with albendazole (10 $\mathrm{mg} / \mathrm{kg}$ for 6 months) was initiated. Surgical intervention was not considered due to the lesions being deep-lying and disseminated.

\section{OUTCOME AND FOLLOW-UP}

After 6 months of treatment, CT imaging revealed a decrease in the size of all lesions with cavitations developing within the right lung lower lobe lesion (figure 1). The patient is under long-term follow-up and remains well.

\section{DISCUSSION}

Cystic hydatid disease is a common zoonosis caused by the larval cysts of Echinococcus granulosus. It is seen worldwide but most cases in Northern Europe are seen in immigrants from endemic areas. ${ }^{4}$

Hydatid cysts are most commonly found in the liver but the pulmonary cysts are not uncommon. Symptoms are generally non-specific but cyst rupture can precipitate 


\section{BMJ Case Reports}
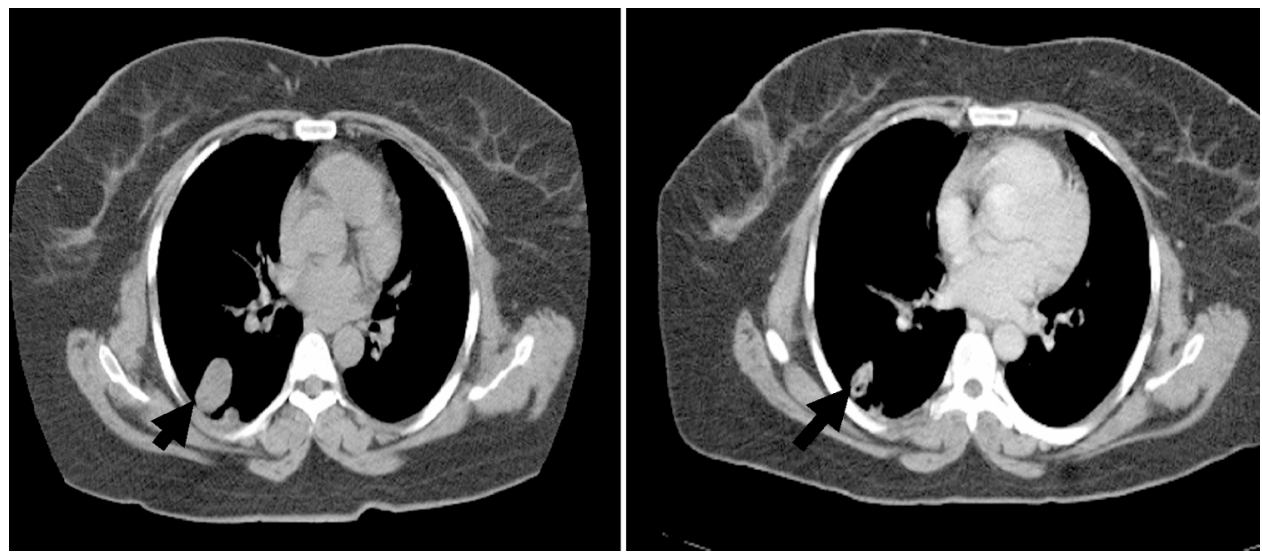

Figure 1 (A) Right lower lobe hydatid cyst on CT scan prior to biopsy (arrowed). (B) Cavitation in right lower lobe cyst on CT scan following 6 months of treatment (arrowed).

severe allergic reactions and disease dissemination. ${ }^{5}$ In our case, iatrogenic cyst rupture triggered the development of an eosinophilic pleurisy.

The diagnosis of hydatid cysts requires a combination of radiological and serological testing. Chest radiographs and CT scans can identify specific features that are strongly associated with pulmonary hydatid cysts. ${ }^{67}$ Comparative studies between serological tests have shown IgG ELISA to be the preferred assay but reliability is maximised by using at least two different tests. ${ }^{7}$ Eosinophilia is found in less than $15 \%$ of patients and is generally only present following leakage of antigen from cysts. ${ }^{9}$

In our case, the eosinophil count was initially normal and CT appearances were not classical for pulmonary hydatid cysts. However, the CT-guided biopsy and subsequent complications could potentially have been avoided had hydatid serology been considered earlier.

Treatment options for hydatid cysts include surgical resection and the minimally invasive puncture-aspirationinjection-reaspiration technique. ${ }^{110}$ The long-term efficacy of treatment with drugs alone is not yet established and this method is generally reserved for inoperable disease. ${ }^{1}$

\section{Learning points}

- Cystic hydatid disease has a non-specific presentation and is often initially mistaken for other pathologies due to a failure to consider the diagnosis.

- In the context of rising immigration and foreign travel, it is essential to take an accurate geographical history to ensure that we consider diagnoses that are compatible with the circumstances of the individual.

- A combination of an appropriate index of clinical suspicion and correct interpretation of radiological and serological tests will enable hydatidosis to be diagnosed in a timely manner.

Competing interests None.

Patient consent Obtained.

\section{REFERENCES}

1. Ayles HM, Corbett EL, Taylor I, et al. A combined medical and surgical approach to hydatid disease: 12 years' experience at the Hospital for Tropical Diseases, London. Ann R Coll Surg Engl 2002;84:100-5. 


\section{BMJ Case Reports}

2. United Kingdom Census, 2001

3. Lawrence J, Jones J, Hill DR. Improving the evidence base for pre-travel advice: the importance of surveillance of travel-associated infection. $\mathrm{Br} J \mathrm{Gen}$ Pract 2005;55:566-8.

4. Ammann RW, Eckert J. Cestodes. Echinococcus. Gastroenterol Clin North Am 1996:25:655-89.

5. Eckert J, Deplazes P. Biological, epidemiological, and clinical aspects of echinococcosis, a zoonosis of increasing concern. Clin Microbiol Rev 2004:17:107-35

6. Koul PA, Koul AN, Wahid A, et al. CT in pulmonary hydatid disease: unusual appearances. Chest 2000;118:1645-7.
7. Babba H, Messedi A, Masmoudi S, et al. Diagnosis of human hydatidosis: comparison between imagery and six serologic techniques. Am J Trop Med Hyg 1994;50:64-8.

8. Zarzosa MP, Orduña Domingo A, Gutiérrez P, et al. Evaluation of six serological tests in diagnosis and postoperative control of pulmonary hydatid disease patients. Diagn Microbiol Infect Dis 1999:35:255-62.

9. Dogan R, Ypksel M, Cetin G, et al. Surgical treatment of hydatid cysts of the lung: report on 1055 patients. Thorax 1989;44:192-9.

10. Ustpns z B, Akhan 0, Kamiloglu MA, et al. Percutaneous treatment of hydatid cysts of the liver: long-term results. AJR Am J Roentgenol 1999;172:91-6.

This pdf has been created automatically from the final edited text and images.

Copyright 2010 BMJ Publishing Group. All rights reserved. For permission to reuse any of this content visit

http://group.bmj.com/group/rights-licensing/permissions.

BMJ Case Report Fellows may re-use this article for personal use and teaching without any further permission.

Please cite this article as follows (you will need to access the article online to obtain the date of publication).

Widdrington JD, Echevarria C, Bone M, Ellis R. Hydatid cysts of the lung. BMJ Case Reports 2010;10.1136/bcr.04.2010.2938, date of publication

Become a Fellow of BMJ Case Reports today and you can:

- Submit as many cases as you like

- Enjoy fast sympathetic peer review and rapid publication of accepted articles

- Access all the published articles

Re-use any of the published material for personal use and teaching without further permission

For information on Institutional Fellowships contact consortiasales@bmjgroup.com

Visit casereports.bmj.com for more articles like this and to become a Fellow 